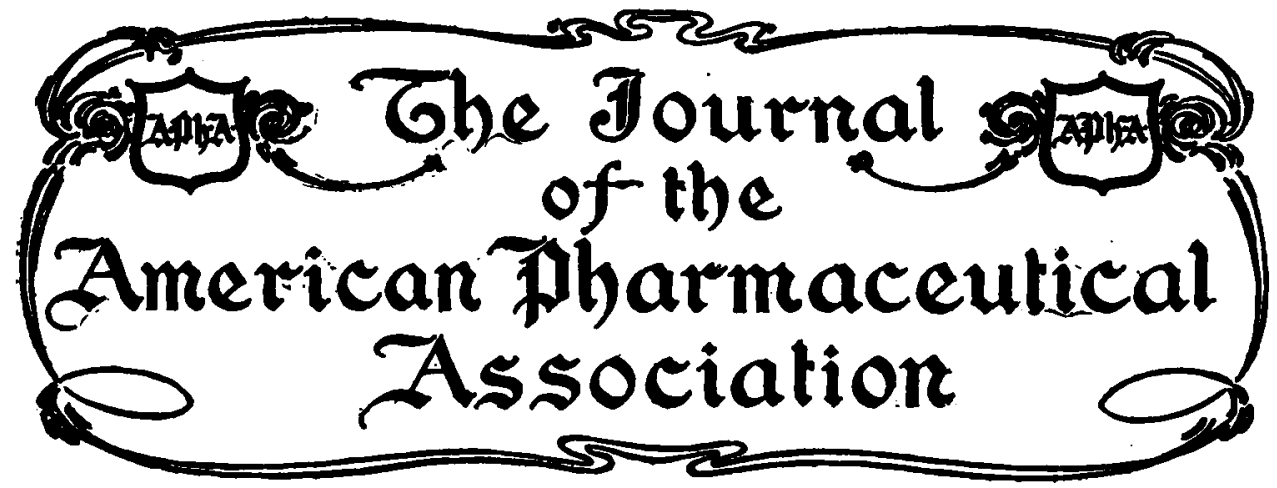

\begin{tabular}{lll}
\hline Volume III & DE C E M B ER, 1914 & No. 12 \\
\hline
\end{tabular}

Office of Publication, 63 Clinton Building, Columbus, Ohio.

Subscription, \$4.00 per annum, within the United States. To Canada, \$4.35. To other foreign countries in Postal Union, $\$ 4.50$ per annum. Single copies, 35 cents.

Entered at the Postoffice at Columbus, Ohio, as Second-Class matter.

\title{
HISTORY OF THE AMERICAN PHARMACEUTICAL ASSOCIATION. SECOND DECADE-1860-1870.
}

WILLI.IM C. ALPERS, SC. D.

The second decade of the American Pharmaceutical Association began under the most trying and discouraging conditions. The Civil War had rent our great country asunder and men who a year before parted as friends were now ready to fight each other on the bloody field of battle. Business was demoralized and the hearts of many, even the bravest, were filled with anguish and apprehension for the future.

The tenth annual meeting, which should have been held at St. Louis, was abandoned, but the following year in 1862, the old guard of the Association, mostly its founders, convened at Philadelphia, Henry T. Kiersted, of New York, presiding in the first part, and William Procter. Jr., of Philadelphia, in the second part of the meeting. In his address Mr. Kiersted says :

"Yet, discouraging as the prospect is, and crippled as we are in the compulsory absence of so nuany of our associates, your Executive Committee had determined that we should yield no longer to the blast. One annual meeting has been omitted; our duty to ourselves, to the profession, and to the commu!nity st!mnons us once more to the work."

The attendance was naturally small, only twenty-four being present at the roll call, but these were joined by seventeen more in the course of the meeting. Many were the letters of regret from the friends of Pharmacy, some being unable to attend owing to heavy loss through the inclemency of the times, others having been deprived of their sons and assistants on account of the War, and some had gone themselves to offer their lives for their country.

There was a spirit of sadness and gloom over this meeting, for timid hearts feared that it might be the last of the Association. Many other associations had disbanded, social, scientific and commercial ones, owing to the severity of the times 
and it speaks well for the determined spirit of the founders of the Pharmaceutical Association that, in spite of all the gloomy surroundings, they found time and courage to assemble. Another trait that was observable was that no word of complaint was uttered against those who had formerly met with them. It was President Kiersted who, two years ago, had expressed the hope that the threatening clouds might pass by. Now he mentions the fact, "that many of ourselves should soon be personally enrolled in vast hostile armaments, whose every movement should carry death and desolation into regions then smiling with plenty and happy in peace; that the arcana of our own science, consecrated, as it is, to the cause of humanity ard to the preservation of health and life should soon be explored to furnish some means of destruction hitherto unknown to the art of war." And from the report of the Executive Committee, the following quotation might be made:

"Joseph Laidley, it will be remembered, attended our last meeting at New York, and was one of the very few Southern members there present. Mr. Laidley was of Irish descent, and was educated in Philadelphia, where he resided until he attained his majority. Having graduated at the College of Pharmacy in Philadelphia in 1850 , he soon afterwards moved to Richmond, Va., where he continued to reside until his death in May, 1861, which occurred in a shocking manner, from the premature explosion of a quantity of fulminating mercury, in the preparation of which he voluntarily engaged for the Confederate authorities. Mr. Laidley was formerly an active member of this Association and in 1854-5, was one of its Vice-Presidents. As a pharmaceutist he was able and energetic and has left on record several papers and essays."

You will see that there was no harsh criticism, no sign of anger against the members who had considered it their duty to fight for the cause of the South; there was nothing but friendship and brotherly feeling. And another quotation from the same report says:

"Charles A. Junghanns, attended our last meeting, having recently before visited his friends in Germany. He was an earnest man, and as a pharmaceutist stood well with his brethren. When the dark cloud of disunion first threatened the West, Junghanns raised a company in Cincinnati, and as its Captain joined the army of Buell. Naturally not robust, the exposure incident to his new life, affected his lungs. At the battle of Shiloh, his loss of voice having rendered him unable to perform his duty as an officer, he deliberately put his first Lieutenant in command of his company, and taking a rifle fought with great coolness and decision, until he fell from a wound in his head. Mr. Junghanns was an advocate of pharmaceutical education, and in his death our Association has lost a valuable member."

Here we have a brother pharmacist who gave his life willingly for his country He was one of the many heroes whose names history does not recount, who did his duty without complaint, without hope of reward, without flourish of trumpet, or limelight exhibition. He went, he fought, he died. Can there be anything nobler and finer as a testimonial than the few simple words written probably by Mr. Procter, President of the Committee? Neither great monuments nor flowery speech could do more to show the spirit of devotion and patriotism that prevailed among the pharmacists of those days.

The meeting itself moved in a quiet, mostly scientific way. There were a great many queries, these having accumulated for two years, and many interesting papers were read. It is to be remembered particularly that Professor Maisch at that time emphasized the idea to encourage the wine growers of the United States to save the tartar deposits. We quote him as follows:

"Resolved, That we regard the production of tartar from American wine of great im. portance, on account of the extensive uses in which that product is applied in Pharmacy, domestic economy and the arts; that we believe that crude tartar and purified (cream of) 
tartar will always meet with a ready sale, and that the wine growers will advance their own interests and assist in developing the resources of American agriculture, by making the experiment of saving the tartar."

In this one advice, as well as in many others, we see the national spirit trying to encourage domestic industry and enterprise.

Up to this time there had always been a Committee on Adulteration, and it was moved at this meeting, by Dr. Squibb, to discontinue this committee and appoint in its place a committee of five to be called the Committee on Drug Market.

"Resolved, That the Committee on Adulteration be discontinued, and a committee of five be appointed to be called the Committee on the Drug Market, whose duty it shall be to report annually the fluctuations in the supply and demand of drugs, the variations in quality. and adulterations and sophistications coming under their observation, or reported to them by others; and that they be authorized to make a report on any adulterations and sophistications of immediate interest, through the pharmaceutical journals, as soon as practicable after their discovery; and that all members are requested to furnish information of the kind required, without unnecessary delay."

The larger part of the proceedings, was made up of the report of the Progress of Pharmacy, which, owing to the lapse of two years, contained a great deal of interesting and valuable information. It treated particularly of pharmaceutical preparations, materia medica and subjects of historical value; for while most of the investigations and recommendations contained therein have now become familiar facts and rules in Pharmacy, they yet show that, in a great many instances of important chemical and pharmaceutical developments, the first instigation came from the American Pharmaceutical Association.

In spite of the small attendance and the discouraging outlook under which the Association assembled, the spirit for the elevation of Pharmacy and purity in actions and deeds, remained undaunted, as can be seen by the expulsion of a member of the Association, Mr. Hunewell, of Boston. He had used the title and seal of the Association for improper advertising purposes. An effort of this ex-member to be reinstated in 1867 failed, the Association refusing to re-open the case. This is the first expulsion of any member from the American Pharmaceutical Association. The meeting adjourned to meet again in Baltimore, under the presidency of William Procter, Jr.

At the meeting in Baltimore in 1863, there were forty-nine members present. The address of the president was made in a quiet, sober and business like tone. He forecasts a financial difficulty that he thought would befall the Association. According to the Constitution, members who had paid their dues for ten years, became life members and were exempt from further payments. Mr. Procter pointed out that, in a year or two, most of the active members would, according to this clause, cease to pay, and as the increase in membership, owing to political difficulties was not very great, he feared that the Association was approaching financial bankruptcy. This question gave rise to a number of debates in this and following meetings. The president proposed that a life member should pay $\$ 1.00$ annually; others proposed that they should pay the cost of the proceedings and so on, but nothing definite was done in this matter for a number of years.

Mr. Procter's remarks on the Pharmacopoia were of particular interest as they show of how little account this valuable book was held at that time. He says:

"It is time that our practitioners of Pharmacy of every grade should know that we have a United States Pharmacopoia, by personal inspection. Hundreds, perhaps thousands, have 
never seen the work and know it only through the several commentaries and more particularly that in the U. S. Dispensatory, which work is often confounded with the Pharmacopoia."

\section{Before closing this address, he says further:}

"I would fain re-impress on you, fellow members, the need we have of more earnestness-I might say enthusiasm - in order to carry forward the several objects of our association with zeal and success. Already our national Association, through the proceedings and manner of organization, is attracting notice abroad, and our co-laborers there are looking to us for fruits proportioned to the profession we make. Let us then individually interest ourselves in the work of progress-each in his own way; and by well directed efforts at home, among our fellow pharmaceutists let us increase our members so as eventually, if possible to include all the better qualified and liberally disposed pharmaceutists and druggists in the whole country. That our Association has been able to keep up its organization, in the face of the discouraging circumstances which now surround it, is to me, gentlemen, a strong evidence of its vitality, and leads to the assurance that when peace once more smiles upon us, our Society will, with a due amount of esprit de corps, become an honor to American pharmaceutists, and command the respect of our brethren everywhere."

Acting on the recommendation of the president, in reference to the Pharmacopœia, resolutions were afterwards proposed by Dr. Squibb, and also by Mr. Parrish, recommending the use and study of the Pharmacopoia to pharmaceutists and physicians and establishing a permanent committee on the Pharmacopoia, consisting of three members, to keep a current commentary on the Pharmacopoia and a record of all useful criticisms and suggestions. The president appointed for such a committee, Dr. Squibb, William Procter, Jr., and Alfred B. Taylor, probably the ablest men who could be found for this purpose in the Association.

Among the queries and articles presented to the Association we notice a great many in which the desire is expressed to develop the cultivation and exploitation of indigenous plants for pharmaceutical purposes. Of interest is also the thirtieth query: "What course should be adopted by Pharmaceutists in view of the present state of the liquor market, as regards factitious Brandies and Wines?" It will therefore be seen that this vexed question, that agitates us still to-day, is as old as the Association.

The Association at that time was aware of its important influence and at the time entertained a friendly spirit for our co-workers in other countries, as seen by the resolution offered by Mr. Parrish, which is well worth producing at the pres. ent time; and is as follows:

"WhEREAs, The mutual cultivation of science tends to break down sectional and national distinctions, and to unite all of kindred objects and pursuits in a common bond of friendship and good will, and whereas, we have learned with satisfaction of the Druggists and Chemists of Great Britain having been summoned near the same time as our present meeting. and as we believe for purposes similar to our own; therefore,

"Resolved, That we view this movement on the part of our brethren of the mother country with feelings of satisfaction and encouragement, and invite their friendly cooperation and correspondence in advancing a knowledge of the science and the art of Pharmacy, and in promoting the elevation of the profession to a position commensurate with the importance and dignity of its objects.

"Resolved, That a copy of these resolutions, signed by the proper officers of the Association, be transmitted to the President of said Conference of Druggists and Chemists of Great Britain by our corresponding secretary, who is also directed to solicit an exchange of their published proceedings for those issued by this Association."

From the Report on the Progress of Pharmacy, we learn that of all the pharmaceutical journals that had existed in the United States before the beginning of the Civil War, only two had been able to survive, namely the American Journal of Pharmacy and the American Druggists Circular. All others had succumbed. A 
timid effort is made in the report to condemn proprietary medicines, although no action was taken. The Committee says:

"Several of our German contemporaries have undertaken the task to clear up the mysteries or mystifications of some proprietary medicines sold in Germany and elsewhere at extravagant rates, to the great detriment of legitimate pharmacy. An undertaking of this kind in our country might be attended with benefit; at the same time, however, it is to be feared, that the very opposite of the interests of science and humanity, would almost to a certainty be the gainers, as it would only add to their notoriety."

Of considerable interest are some data given in the report of the Committee on the Drug Market, that had been created the previous year, and presented its first report. It gives us some idea of the value of the drugs in those days, for instance:

"Alcohol: Among the articles of primary importance which have fluctuated largely ir. price, alcohol holds a prominent place. Of the various grades of alcohol, that called 95 percent. or the Alcohol Fortius of the present Pharmacopoeia, may be taken to represent the whole. At the commencement of the Association's year, namely September, 1862, it sold at 65 cents per gallon. From this it rose, with occasional fluctuations, during the remainder of 1862 to 81 cents, being once as high as 90 cents. By the end of January, however, it reached $\$ 1.10$, and early in February, brought $\$ 1.25$. Thence it gradually declined to 95 cents without much fluctuation till the present time, when it varies with the price of whiskey, between 90 cents and 95 cents."

"Ether: The price paid for ether varied from 35 cents to 37 cents, at one time being as high as 68 cents, there being no relation whatsoever between the price and quality, nor even between the price and strength."

"Chloroform: Ten specimens were examined. Nine of the ten were of full official density. and, judging from the bottle, label and quality, seven of these were from the same manufactory. Not one of the ten was up to the standard, in freedom from foreign compounds, though five of them were so nearly up to it as to be considered very good chloroform. The remainder were less clean though, with one exception, not very unclean. One specimen was very bad, unfit even for external use. The price paid for these were 90 cents to $\$ 1.50$ per pound."

Most interesting is the report on Tincture Opii, which says :

"An accurate morphia assay is, however, one of the most difficult in the whole domain of of ordinary chemical research, requiring more time and skill than was at the command of the Committee. It was therefore determined, by experiment, that a uniform process for precipitating all the alkaloids could be adopted and relied upon, as giving a tolerably close comparison of the narcotic value of the specimens to which it was applied. Fifty cubic centimeters of the Standard Tincture of the Pharmacopoia, yielded 0.604 grammes of mixed alkaloids by the process adopted. Eleven specimens treated precisely in the same way gave the following results, namely: $.424, .327, .343, .308, .486, .427, .480, .427, .340$ .338 , and .357 . These figures indicate that one of the specimens is just about half strength Five are in the neighborhood of $7-12$, and the remaining five between eight and ten-twelfths of the official strength. These preparations cost 1.00, 1.00, 1.12, 1.00, .88, 1.06, unknown, unknown, 1.12, and 1.00 per pound.

"Opium, by the case, in the hands of the importers, has brought an average price of, at least, $\$ 8.50$ per pound throughout the past year, and this opium in drying loses an average of 20 percent. in weight and there are about $141 / 2$ troy ounces in the avoirdupois pound. while each pound of the official Tincture represents $1 \frac{1}{4}$ troy ounces of the dried and powdered opium. Therefore, at the net case price of opium, the quantity represented in a pound of properly-made tincture costs over one dollar. Now, upon the theory that the druggists are generally honest, and are selling their tinctures below net cost of the principal ingredients, regardless of the cost of menstruum, time, labor and general expenses-to say nothing of profits - this preparation may be all right, if the above examination be all wrong. But if this theory be too absurd for general credence, then these druggists and pharmaceutists are chargeable in their practice with an amount of dishonesty which, in the shape of a more bold and manly variety of robbery, would be likely to restrict their opportunities of wrongdoing to the narrower sphere of the criminal prisons."

Among the papers presented at this meeting, were two of particular interest, both treating of a still for apothecaries. One was presented by William Procter, Jr., and the other by Thomas Wiegand. Cuts for stills, as they proposed them. were given and we notice that these identical cuts are still used to-day in the various books on pharmacy. The most interesting paper of the meeting, was furnished by Mr. Procter on Fluid-extracts. In a most exhaustive and scientific 
way, he again goes over the subjects as he did some years ago. But instead of treating all drugs alike as he did in his essay in 1859, he now divides them into four classes, as follows :

Class $I$. Alcohol Fluid Extracts, with a number of sub-divisions according to the strength of alcohol of the menstruum.

Class II. Acetic Fluid Extracts, menstruum diluted alcohol, or alcohol, with a portion of acetic acid intended partly for preservation, but mainly for retaining important volatile ingredients.

Class III. Saccharine Fluid Extracts; these fluid extracts are prepared with water or diluted alcohol as a menstruum; but little if any of the alcohol is retained in the preparation when finished, which is preserved by the agency of sugar; also having a number of sub-divisions, according to the strength of the menstruum.

Class $I V$. Various unclassified fluid extracts.

The paper is too long for reproduction in toto, but it would be well worth while for a historian to collect all the various papers on fluid extracts and combine them into a history of these important preparations.

Other papers of interest were, "On the Internal Revenue" by Edward Parrish. Owing to the difficulty of raising revenue, new laws of various kinds were repeatedly passed by Congress, and Mr. Parrish gives some interesting advice and consideration which our law-makers of today might do well to heed.

Frederick Stearns presented a paper on æsthetical pharmacy in which he makes a plea for more accuracy and neatness in the fixtures and arrangement of the stock in the pharmacies of those days. The volume closes with one of the nicest little papers ever written, called a "Plea for the Handmaiden," by Mr. Parrish, in which he compares pharmacy and medicine, and comes out in sweet, gentle and yet strong words for the recognition of Pharmacy as a profession. He closes with the words:

"Let me not be charged with hostility to the medical profession. My earliest recollections and life-long associations have taught me to love and honor the high-minded physician who, with zeal for both science and humanity, devoted his life to the most laborious and responsible of pursuits; but this very respect for the physician as he should be, induces me to place a proper estimate upon the Physician as he often is, and to protest, in the name of common honesty and fair dealing, against the unprofessional favoritism to which I have alluded, as being notorious, especially in our large cities. And now, entering into the second decade in the history of this Association, let us assert for American Pharmacy the claim, founded on a common origin and kindred objects, but as a modest and docile sister to a place beside the numerous and distinguished branches of the medical family. May we all strive to deserve such a position."

The observant reader of this volume of the Proceedings, in which two of the most prominent teachers of pharmacy in those days, William Procter, Jr., ancl Edward Parrish, presented a number of papers, cannot but notice the difference of style and expression between these two men. Procter is always quiet, calm and sober. He thinks clearly and sharply, and expresses his thoughts in a simple but convincing manner. Parrish, the greater scholar of the two, and a great reader of history and poetry, likes to use flowery and elegant language; and particularly when his heart enters into the argument, as in the last mentioned article of the Handmaiden, he seems to rise to higher spheres, and his language flows like a refreshing, rippling stream among the fragrant flowers of the forest.

Mr. J. Faris Moore, of Baltimore, was elected to preside over the next meeting of the Association, appointed to be held in Cincinnati, in 1864.

The twelfth annual meeting of the Association convened in Cincinnati, Ohio, 1864 , and was in more than one respect, a continuation of the preceding one. There 
was the same spirit of apprehension and uncertainty, although hopeful signs had already appeared on the horizon. At the opening of the meeting there were twenty-five members present, and a few more arrived later. A few of the leading men of the Association had died during the year, the principal ones being Franklin Bache, of Philadelphia; John Meekim, of New York, one of the earlier presidents of the Association, and George W! Weyman, of Pittsburgh; Pa.

In the nomination of candidates for the presidency, a small change was instituted by nominating three presidents, the reason being, to do away with the precedent of electing a president from the city in which the Association was to meet, as it might happen that such a course would be inexpedient, and, besides, would always exclude worthy members from being candidates from towns where the Association would not be likely to assemble. In spite of this change, however, the habit of electing a president from the place of meeting continued for a number of years. At Cincinnati W. J. M. Gordon was elected president for the following year.

A great deal of the time of the twelfth meeting was taken up with the discussion of certain changes in the Constitution, the principal one being the permanent election of the Recording Secretary with an annual salary of $\$ 100.00$, and his traveling expenses. This innovation caused a great deal of opposition in the beginning, but it was adopted subsequently. Another vexing question was that of admission of new members. There were at that time the names of many men on the roster who had never signed the Constitution and had never paid dues, and it was pointed out that in the selection of new members greater care should be exercised and no one should be considered a member and receive the proceedings, unless he had paid the dues and signed the Constitution. This question occupied the attention of the Association for many years afterwards. Another change of the Constitution was the creation or the establishment of five standing committees, elected annually, instead of two as before, the five committees being, the Executive Committee, the Committee on Progress of Pharmacy, Committee on Drug Market, each to consist of five members, Committee on Scientific Queries and a Business Committee, each to consist of three members. These resolutions were also adopted at the following meeting, so that the Constitution after the thirteenth meeting contained considerable changes from the original draft.

The report of the Committee on the Progress on Pharmacy contained some information of great interest on the education of the young pharmaceutists in various countries and a comparison was made between education in these countries and the total absence of any rules or regulations in this respect in our country. Strong recommendations were made to use all possible means of bringing about a better education of the apprentice.

The Committee on Drug Market brought in a report that filled more than twenty pages of the proceedings and which contained accounts and complete price lists of various drugs. Owing to the political difficulties, it can be understood that the cost of some of the drugs had risen to an enormous price, we notice for instance that morphine sulphate cost $\$ 11.00$ an ounce, potassium iodide $\$ 7.00$ per pound, quinine sulphate $\$ 3.55$ per ounce, glycerine $\$ 1.75$ per pound for the English, and, for the American, .75 to $\$ 1.50$ per pound. The report, written probably by the Chairman, Mr. Maisch, again makes a strong plea for the cultiva- 
tion of indigenous plants and the promotion of domestic industry in pharmaceutical and chemical matters. It says :

"Another important and extremely interesting feature, that might be embraced in one of these reports, is the actual supply to our various markets of indigenous plants and drugs. We ought to regard this in connection with the source of this supply as of the utmost importance in order to prevent, if possible, the extermination of medicinal plants in certain localities. We are in the habit of denouncing the short-sightedness of the governments and the population of the South American republics in felling the cinchona trees, for the purpose of obtaining their valuable bark, instead of carefully nursing them, with the view of preserving them until they have yielded the indispensable drug to their utmost capacity; we applaud the Dutch and English governments for their well directed efforts to transplant the cinchonas to the congenial climate of the East Indies, because we hope that if successful, the calamity of an insufficient supply of cinchona bark will be prevented. And yet what are we doing at home? The writer knows that in years gone by, spigelia, senega. serpentaria, ginseng, and probably other drugs used to be collected in the East, but have become almost completely extinct there, so that we had been compelled to look to the South for a sufficient supply, and, since this source has been shut off, to the young and growing states of our great West. It is within the writer's knowledge that, in certain localities in the immediate neighborhood of Philadelphia, cimicifuga, sanguinaria and veratrum viride have almost or entirely disappeared, and it is likely to be so in other places.

"In view of the growing importance of these drugs, does it not become us to pause and reflect upon proper means to be adopted to prevent their complete eradication? Is it perhaps not similar with podophyllum, the use of which appears to have largely increased in late years? With a soil adapted to as large a number of vegetable species as can be found anywhere throughout the world; with a climate reaching almost to the tropics of the South, and extending through the entire fertile part of the temperate zone; with a continent stretching from the shores of the Atlantic to the coast of the great Pacific Ocean. and embracing towering mountains, undulating hills and large plains; we ought never to come under the necessity of seeing our own medicinal plants transferred to other con. tinents in order to prevent an exhaustion of supply."

If we turn to the scientific papers presented at this meeting, we find the first paper presented by our old and highly respected member, C. Lewis Diehl, at that time from New York, on Oleum Aethereum. He had joined in the year 1863, as well as another old and highly respected member now deceased, namely, Albert $\mathrm{E}$. Ebert, of Chicago.

Among the papers presented the one by Mr. Gordon, of Cincinnati, on Glycerin, deserves notice. Glycerin was at that time a new article, and Gordon speaks of "its mission as a remedy, as an adjuvant and as a solvent." His paper was in those days a revelation to most of the hearers. Another subject that was new to most of those present was that entitled "Remarks on Dialysis," by William Procter. Jr. While the investigations of both these men, and the information that they gave in their respective subjects, are now common knowledge to every chemist and pharmacist, the appearance of these two papers at this time shows of what strict and keen scientific spirit the early leaders of our Association were possessed and how nothing escaped them that seemed to be of any use or value in their profession. Mr. E. Parrish read a volunteer paper on the "Systematic Course of Study and Manipulation for Students of Pharmacy." He gives in it a complete syllabus for students and pleads in a masterful way for higher education.

The thirteenth meeting of the Association was held in September, 1865, in Boston, and was called to order by Mr. Gordon, of Cincinnati. At this meeting over one hundred members were present and a livelier and more animated spirit seemed to prevail. It certainly was one of the most interesting and spirited meetings, in so far as a full exchange of opinions on many subjects took place, in which the leading men of those days often differed. It is natural that the president should make some reference to the close of the destructive war. He says : 


\begin{abstract}
"As members of a scientific Association, baving for its main object the advancement of the members of our calling in elevating and useful knowledge, we have as a matter of course nothing whatever to do with politics; our boast is that we meet on the common ground of a brotherhood which interferes not with the religion or politics of any of the members. We feel, therefore, that we have nothing to do as a Convention, assembled for such purposes as I have indicated, with the war (which is now happily closed), other than to deplore its necessity, to mourn over the separation it has caused us for the time being, from many of our brethren; to regret the hindrance it has been to the advancement of our cause, and to rejoice (which we heartily do), in its termination. Many of our members, particularly in the Southern States, have been practically cut off from connection with our Association during the last four years, and their vacant places have been the cause of no little sorrow for those of us who were enabled to meet. I think I express the sentiments of every member of the Association, now met in our annual conclave, when I say that our doors stand open to all those who have been hindered from meeting. with us, and a hearty welrome awaits them."
\end{abstract}

The president also dwells on the many taxes that had been levied during the war and which brought about an increase in the prices of many pharmaceutical and chemical preparations, and he there makes his first plea for free alcohol used as a medicine and in the arts. After nearly fifty years of agitation this same desire still exists.

At this meeting the first mention of an International Congress of Pharmacy is made and while no delegates were appointed it was yet resolved to send a greeting to this meeting, which took place in Brunswick, Germany. It was also resolved, and this is very noteworthy, that the minutes of the first meeting held in 1851 , as well as the proceedings of the Association of 1852 and 1855 , should be reprinted, as no more copies were available.

The report on the Drug Market, which in previous years had been of such interest, was this year missing. A difference of opinion, as to the value of the $U$. S. Pharmacopœia, brought out some very interesting remarks from Prof. Parrish, Mr. Procter, Dr. Squibb and Mr. Maisch, as well as others. The question at issue was, whether a pharmacist should be allowed to differ from the methods and strength of certain preparations as laid down in the Pharmacopœia, and the general opinion seemed to be that, while the Pharmacopœia was a valuable and useful book, nobody should be bound by it because a certain man or some men who had written the Pharmacopoia had advocated certain formulas. The lengthy debate by the leading men of the time was cut short however, by the stern veteran, who always showed a clear judgment and the greatest common sense, S. M. Colcord, of Mass. He said in a quiet way :

"One great object to be attained in the strength of preparations is uniformity. This we cannot get if we differ. There must be some standard; and as long as you adopt the Pharmacopora, you must adhere to it."

Another interesting discussion took place at the beginning of the meeting. It will be remembered that there were a great many of the earlier members who had the idea that the American Pharmaceutical Association should be an Association of delegates and should derive its strength from local associations and colleges of pharmacy. Although this opinion had been defeated at the previous meeting, there were many signs that it still prevailed in the minds of the leading men, and when at the thirteenth meeting delegates from the Alumni Association of the Philadelphia College of Pharmacy presented their credentials, Dr. Squibb abjected, on the grounds that the Alumni Association was not a local association, and that the American Pharmaceutical Association could not recognize any society whose mem- 
bers were scattered all over the United States. This opinion was shared by many, with Mr. Parrish leading the opposition. President Gordon sustained the objection and ruled the Alumni Association out. An appeal from this decision was made and the ruling of the Chair was not sustained. While this incident may appear of little significance to some, it must yet be considered one of the greatest victories for the Association; for it again emphaiszed its national character and absolutely independent position.

It was remarkable that at this meeting a great many new members were added to the roster, the most coming from Chicago, about 25 in all. Here also joined our beloved friend and treasurer for many years, S. A. D. Sheppard, of Salem, Mass.

The various propositions for changes in the Constitution as mentioned previously, were adopted at this meeting and the Committee on Nominations brought in a full list of candidates for all the offices and committees. H. W. Lincoln, of Boston, was elected president. At this meeting the office of Local Secretary was discussed and at the next meeting added to the list of offices. Mr. Ebert, of Chicago, read at this meeting his first paper on "Oil of Amber." He also took part in all the debates with that youthful impulsiveness and enthusiastic courage which characterized him to his death.

Among the queries the one on Opium and its cultivation in the United States, was of particular interest. Dr. Squibb said:

"I hold in my hand a specimen of opium, made from poppy grown in Virginia, in the neighborhood of Lynchburg, by Powhattan Robertson. It is understood that large quantities were made and used in the medical practice of the Southern armies, when they were prevented from procuring from abroad a sufficient supplv of the drub. I would like to have the Association receive it, and refer it to Israel J. Grahame for examination; if he is willing to undertake that matter, it would doubtless be very acceptable to the Association. There is no doubt about its authenticity; it came directly without passing through second hands. I have heard it said that we could cultivate opium in this country; it would be a great advantage."

\section{And again}

"I have heard that the culture of opium was attempted in Alabama and in Florida, in the neighborhood of Apalachicola, to a considerable extent. It was found to be deleterious to the field hands, and was abandoned on that account in some localities. That large quantities were produced seems to be indisputable."

This brought forth the remark from Mr. Henchman, of New Hanmpshire, that :

"During the war of 1812, when opium was very scarce, some parties produced it in New Hampshire, and it sold from ten to twelve dollars a pound. It was then of very good quality. After he had established a market, the producer manufactured a very good looking article but much inferior."

Mr. Parrish read an interesting paper on "Filtering and Filtering Apparatus"; while Mr. Maisch read at this meeting a lengthy treatise on "Rhus Toxicodendron," showing that the poisonous principle in this plant is an acid and not, as was supposed a number of alkaloids.

Thomas S. Wiegand, of Boston, read a paper on "The Obligations of Pharmaceutists in Respect to the Instruction of Those in Their Employ," and made a strong plea for the proprietors to instruct their apprentices better, closing with the words :

"In concluding these hasty thoughts upon so important a subject, I would suggest the propriety of the Association urging, with all its influence, the adoption of some scheme 
calculated to render the practical instruction of pharmaceutical students a leading feature among our members."

It will be seen from these remarks how feebly and how slowly the demand for higher education arose, and how it took from four to five decades to bring it to the present height. Another paper along the same line, was that called "Fidelity to the Pharmacopoia," by James W. Mill, in which he uses a beautiful simile, and says :

"Guided by no such acknowledged standard of authority, the preparation and dispensing of medicines would be involved in extreme confusion and uncertainty. Like a ship at sea without chart or compass, Pharmacy would drift helplessly on the turbid waters of empiricism, and, finally, despite the utmost efforts of its crew, be lost amid the rocks and breakers of quackish pretention, or the sordidness and selfishness of mere trade and traffic. As the compass is to the mariner, so is the Pharmacopoeia to the pharmaceutist, pointing out to him the course by which to steer his pharmaceutical ship, so as to safely guide it into the haven of professional integrity and material prosperity. Itself, indeed, the creature of Pharmacy, it yet in turn aids greatly in its advancement. A standard for the guidance of pharmaceutists themselves, it also furnishes a medium by means of which the physician and pharmaceutist can understand each other in the writing and dispensing of prescriptions. Compiled by able and conservative minds, it is a safe and trustworthy guide, containing within its pages, as it were in a nut-shell, the concentrated results of many previous years of observation and research, thus supplying to all pharmaceutists alike, in a cheap and compact form, the most reliable formulas for the preparation of its various products that science and practical experience have yet devised; fallible, of course, like all human productions, it is none the less entitled to full confidence and support. The Pharmacopoia should, however, be regarded as not simply advisory or recommendatory, but as authoritative."

A number of papers at this meeting dealt with the question of economizing and saving alcohol. Owing to the enactment of new internal revenue laws, the price of a gallon of alcohol had risen from $75 \mathrm{c}$ to nearly $\$ 3.00$ and the question of saving, was of course of great importance. New processes of making tinctures and fluid extracts were recommended and stills of all kinds were presented at this meeting for the recovery of the alcohol used in their manufacture.

The fourteenth annual meeting of the Association was held in Detroit, Michigan, H. W. Lincoln, of Boston, presiding at the first half of the meeting, and the newly elected president, Frederick Stearns, during the second half.

The amendment of the Constitution offered the previous year, to establish the office of "Local Secretary," was adopted in the course of the meeting. Mr. P. W. Bedford, of New York, was elected the first Local Secretary of the Association.

In his address President Lincoln reviewed the activities, the work and the gradual growth of the Association, and attached to it a tabulated statement of the number of members of each state. From this table, in which thirty-two States, one territory, the Dominion of Canada, New Brunswick, and Bermuda were represented, it appears that the number of members had increased since 1853 from forty-four to six hundred and seventy-one, showing a continuous increase with every year with the exception of the last one. This was owing to the fact that a great many members were dropped on account of non-payment of dues.

In the course of the meeting Professor Parrish took occasion to make a few remarks on the facilities of education of pharmacists in the United States, from which we quote the following:-

"There is not a city of the first class in the United States that might not, from the apothecaries residing in it, furnish a sufficient class to sustain a College of Pharmacy."

He then reviews shortly the work of the various colleges and records that the 
attendance is proportionally small particularly in the large cities such as New York and Philadelphia. He then continues:

"Now the question for us to consider is this:-Cannot this Association exert its influence to improve the conditions, and extend the appreciation of the colleges in the United States and to establish others when practicable? In Cincinnati they have not for a number of years had any successful teaching. In none of the cities but New York, Philadelphia, Baltimore and St. Louis are there any colleges attempting to get along and keep up the instruction. I don't know that we could do anything, but I think the weight and infuence of the Association should be thrown in this direction. That is the way in which we are to raise the status of pharmacy in the United States. It is through generations to come. We that have got ahead, and feel like relinquishing our connection with business, .cannot do a great deal except to use our influence in that direction; but the young men themselves, who are to be educated in pharmacy, will raise the American Pharmaceutical Association hereafter to be a body of far greater efficiency than it has ever been, judging from those we have among us who have recently availed themselves of the advantages of pharmaceutical instruction. I hope it will rest in the minds of members of the Association whether we cannot do something to wake up the very large constituency we have to the importance of sending their apprentices and those over whom they have influence, to obtain a systematic instruction in pharmacy."

Frederick L. Stearns took occasion to follow with these words:

"The remarks that have been made by Prof. Parrish, lead me to say a word in regard to the influence of this Association in the respect of the formation of local Associations, not merely educational ones, but societies for mutual improvement other than educational, for social influence and trade infuence. We need to get the druggists together in the towns and let them become acquainted with one another, let them know each other better, so as to rub off the corners, trade-jealousy and antagonisms, which are very apt to exist between members of the same profession. I think the influence of the Association can be brought to bear in this direction with great benefit. Throughout the country the druggists who are not members of this Association, and who do not understand its object look upon it with askant eye. They think that by joining the Association they may involve themselves in some way-they don't exactly understand how-but the very moment they become informed as to the objects, advantages and influences of the Association they are ready to join. I can say for myself that I have been a member of this association for fourteen years and have spent considerable amount of money in attending its meetings, but I know it has paid me ten-fold in a pecuniary sense alone, to say nothing of the many other advantages I have reaped from my connection with it. I am very glad, therefore, that the remarks of Prof. Parrish were made and I cordially endorse them."

The remarks of these gentlemen were not followed by any particular action and it might appear unnecessary to record them in a history of the Association. But deeds and aetions are very often the result of long and quiet agitation and the men in whose minds the first instigation originated are sometimes forgotten as others take up their work and, often, bring it out as their own. It is the office of the true historian to trace the development of the spirit that underlies all great actions back to the originator; and remarks of the kind recorded above, are more apt to act as a leaven and produce great results than strong, impetuous and radical motions of reform. In these few and gentle words, expressed spontaneously in the midst of the meeting, the beautiful spirit of fraternity that characterized the actions of our Association in those days, comes out in a wonderful way and they show how the leading men of those times cast their eyes and thoughts forward and saw in the future that greatness of the Association to which it has grown at the present time.

When we look over the list of the newly-elected officers of the Association, we cannot but be struck with the galaxy of important and great names that we see this year. Many of them were selected for office for the first time, others had 
been working in the interests of the Association since it began. Where could a finer array of great names be found than the following:

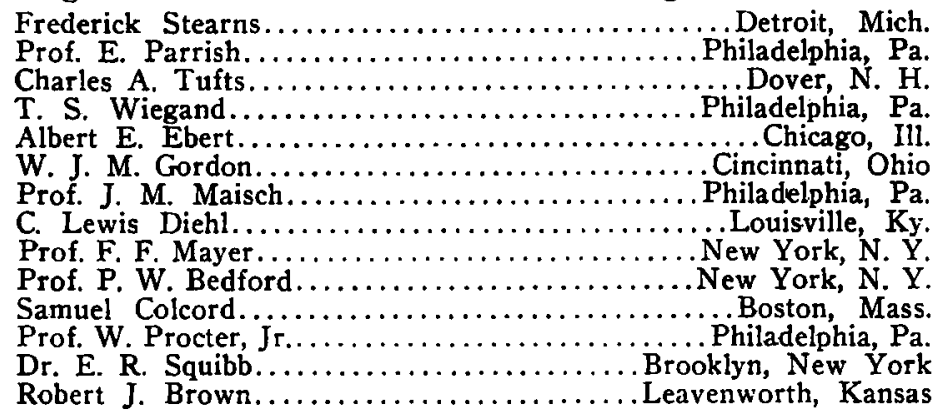

An interesting debate took place when the special committee on the Internal Revenue Law, Dr. E. R. Squibb, Chairman, presented their report. It was again Prof. Parrish, who objected to the number of laws enacted by Congress and he showed how absurd it was to classify all preparations under the same heading. As the Pharmacopoia was no authority at that time, there were, for instance, a great many formulas for Citrate of Magnesia in use, and according to Prof. Parrish's understanding of the law, all of these required a revenue stamp, except the one made by the formula of the Pharmacopoia, which he claimed to be the worst of all. His own preparations, that were prescribed by physicians all over the country, came under the same class, simply because in some of them he deviated slightly from the formulas of the Pharmacopœia. Dr. Squibb defended the action of Congress and the committee, and a careful perusal of the whole debate shows that the difficulty actually arose from the fact that there was no established standard or authority for any preparation whatsoever.

The Treasurer's report caused lengthy remarks. It had been necessary to levy a special assessment in order to avoid a deficiency, and the treasurer again called attention to the fact that the life members who were exempt from payment were increasing at a rate greater than new members could be procured and earnestly urged relief in this respect.

A number of amendments to the Constitution were proposed. It took however another year until final relief on this vexing question was found.

Delegates were also appointed for the next International Congress held in Paris in 1867.

The report on the Progress of Pharmacy, presented by the Chairman, Enno Sander, comprising about sixty pages of the proceedings, was a very exhaustive treatise on everything that had happened in the previous years in the line of pharmaceutical development. As a peculiarity, it might be mentioned that in nearly every report at those times, the formulas for Syrup of Copaiba and Syrup of Cubebs are given, preparations that have long since disappeared from general use. The Chairman pointed out the difficulty of compiling this report and makes the remark:

"It occurred to my mind that all these difficulties might be obviated to a great extent by appointing a permanent reporter on the Progress of Pharmacy."

This is the first mention of a "permanent reporter on the Progress of Pharmacy." 
Interesting papers were presented on the production of wines in various parts of the United States. Albert E. Ebert, from Chicago, presented specimens of Essence of Beef, the first made in this country. From the scientific papers, we notice a great many in this year that contained reports on the improvement of the processes in Pharmacy, as for instance:-William Procter on Sassafras; James W. Mill on Granular Salts; Thomas Doliber on Benzoinated Lard and Valerian; Wilson Pile on Acetate of Ammonia; C. Lewis Diehl on Chemical Processes; Notes on Liquor Bismuth by George F. H. Markoe; and John M. Maisch on Chloroform, on Brandy and on Sherry Wine.

A paper of some historical value was that by Prof. E. Parrish entitled, "A Discourse on Titles." As has been stated, the general name for the members of our profession was Pharmaceutist. In this paper, Mr. Parrish proposes the name Pharmacist, and the word "Pharmacal" instead of "Pharmaceutical."

Dr. Squibb agreed with Prof. Parrish and said: "I consider the term Pharmacist a decided improvement on Pharmaceutist." No action was taken on this point however, and the proceedings continued for a number of years to speak of "Druggist and Pharmaceutist."

The following meeting, the fifteenth, was held in New York in 1867. Owing to the sickness of President Stearns, the Vice-President, Mr. Parrish, presided at the first half of the meeting. This meeting was a note-worthy one in more than one respect. There were nearly 100 members present. As new members at this meeting, mention should be made of Joseph P. Remington, of Brooklyn, and Dr. C. F. Chandler, of New York. Important changes in the Constitution were made so as, finally, to relieve the strain on the treasury. They all tended to raise more funds and an admission fee of $\$ 3.00$ was required. The annual contribution was to be increased to $\$ 3.00$; life membership abolished for the future. The fee for the certificate of membership was made $\$ 5.00$. After long debates on these propositions, they were finally all passed. A great number of the old members resigned their life-membership and continued to contribute like ordinary members. When the Nominating Committee brought in their report, they named Dr. E. R. Squibb, of Brooklyn, for President. Dr. Squibb, however, declined, stating that stress of business prevented him from accepting the office. He asked the Association to substitute the name of J. Milhau, of New York, in place of his own. After a lengthy debate this was finally done, and Milhau was elected President for the following year.

The report of the Committee on Drug Market, which comprised thirty pages of the proceedings, gives a general review and has tabulated statistics of imports in the different ports of entry, giving the amount of importation and the values. This gave rise to a lengthy debate, in which all the leading men of the time participated. The pictures that were revealed of the status of the drug market in the United States were not pleasant ones. Adulteration and sophistication were the rule, and articles intended to sell as adulterants for staple goods were openly advertised as such, as, for instance, Cream of Tartar was adulterated with a series of anticles, one called terra-alba and claimed to be "the best and most reliable adulerant of Cream of Tartar." Dr. Squibb stated that in the United States. there was "pure Cream of Tartar;" next "Cream of Tartar," then came "Cream 
of Tartar No. 1," "Cream of Tartar No. 2," and so on. No. 1 contained about ten percent. of adulteration, while the lowest grade contained nearly $80 \%$.

Complaints were also made about the varying price of Alcohol, which fluctuated between three and four dollars per gallon.

At this meating, for the first time, delegates to the International Pharmaceutical Congress made a report to the Association, which in many respects is of great interest. The two delegates who had attended the Congress were William Procter, Jr., and John Faber. Mr. Procter received the honor of being elected one of the Vice-Presidents for the next Congress. At the deliberations of this Congress the delegates from America were as a rule on the negative, voting on all questions alone and against the delegates from Europe. Some of the questions discussed were the following:

"Shall there be unlimited liberty as in ordinary mercantile business? Shall there be a free practise with the guarantee of a diploma and personal responsibility under the common law? Shall there be a wise regulation by law, designed to insure the public interests and pro. tect the pharmaceutists?"

All the delegates voted against the first query; on the second, all voted on the negative except those from the United States. When the third was voted upon, all the votes were cast in the affirmative, excepting those of the United States, which were for the negative.

The second question was: "Is it proper to limit the indefinite multiplication of pharmaceutical shops?" It was referred to a Committee consisting of one member of each country. All reported in favor of limiting the trade except Mr. Faber, of New York, who alone voted in the negative.

The third question was: "Is it proper to demand the creation of institutions of a disciplinary character, destined to maintain the 'honorability' of the profession of Pharmacy, by insuring its correct practise, and to represent and protect it in all its exterior relations?" The committee to whom this was referred reported in the affirmative, which view was adopted by the Congress. The delegates' report then stated:

"As some of the speakers had alluded to pharmacy in America in a way that was calculated to give a wrong impression,-a short statement was prepared by one of us, and permission was obtained to read it in English, so that it might go on record. The origin of the colleges was referred to, and the rise of scientific pharmacy, in the United States, to the separation of dispensing from the practice of medicine. A general view was given of our progress and allusion was made to the subjects of the Pharmacopocia, and to weights and measures."

The repont of the Committee on Internal Revenue Law was also of great interest, as it gave the details of a suit by the government against an illicit distiller. In the course of the testimony, two witnesess stated the proportions and yield of the process.

"A quantity of twenty bushels of grain for making a mash, generally consists of fourteen bushels of Indian corn, four bushels of rye, and' two bushels of malt, though a much larger proportion of rye is preferred where a fine quality of whiskey is aimed at. The proportion of water used in making the mash, was the subject of investigation, as affecting the issue of a case on trial. According to the evidence for the United. States, thirty-four gallons of water were usually added to each bushel of grain in the mash, while the beer, after dilution with cold water, usually contains forty to fifty gallons to a bushel. The best temperature for 'mashing' was stated to be from $158^{\circ} \mathrm{F}$. to $190^{\circ} \mathrm{F}$."

The methods adopted by the Government to prevent improper manufacture of 
alcohol and whiskey, were discussed at length in this report, but no action of any kind was taken.

The report of the Reporter on the Progress of Pharmacy comprised 144 pages, more than one-third of the whole book, and it gives an idea of the enormous amount of work that the Reporter, C. Lewis Diehl undertook in the interest of Pharmacy. Among the many interesting new articles that this report contained we notice Liquid Soap mentioned for the first time and the method of its manufacture from glycerine, oleine and solution of potash. Also "Liquor Carbonis Detergens," a new form of antiseptic for local application, "was said to be an alcoholic solution of coal tar, containing probably carbolic acid and other acids, with dark tarry matter. It forms a permanent emulsion with water." The Solution of Citrate of Magnesia continued to be a puzzling question and four different formulas for this preparation are given.

A good idea of the amount of care that the leading pharmacists took in those days in the preparing of prescriptions, is given in the discussion of a paper, in answer to Query 16, by James W. Mill on Ergot. Mr. Maisch stated that he only powdered two drachms at a time, which took about an hour. He said:

"I will cheerfully add my testimony to the fact of the efficacy of ergot when freshly powdered. I disagree with Mr. Wiegand of the necessity of powdering it for immediate use. As I powder it, it would take me about an hour to powder two drachms. I have a practise of never keeping on hand more than two or three drachms. Powdered ergot is never kept more than two or three weeks-when that time has elapsed, it is thrown away and another portion is powdered and kept on hand; two drachms being about enough to use for one or two prescriptions. The physicians who have used it bave been very well satisfied with it. I pass my powder through a sieve of sixty, and that is why it takes a good deal of trouble."

A remarkable resolution was offered by William A. Brewer, of New York.

"Resolved, That while we hold to a high appreciation of the beneficial influence of the accustomed social entertainments tendered to the members of this Association and their friends, by the members of the drug trade in the various cities where the Association meets from time to time, and while we cherish with gratitude and thankfulness the good feeling which prompts these munificent exhibitions of generosity, we cannot but hope that, hereafter, the solicitors of the contributions for such purposes, may get permission from the donors to devote a moiety of said contributions to the endowment of a central library and a cabinet of materia medica and collateral matters for the purposes and use of the Association."

This resolution was later on discussed but not accepted. It is the first crude idea of creating a permanent home central library and museum for the American Pharmaceutical Association.

A communication from the East River Medical Association of the City of New York, signed by Dr. J. Shrady, condemning the renewing of prescriptions, did not meet with the approval of the Association and a somewhat evasive reply was given.

In the report of the Committee of Queries which was read by Mr. Squibb, it is noticed that in the seventeenth query the word "Pharmacist" is used. This is the first time that this form is used in an official paper of the Association.

"What is the best scheme of practical instruction for young men preparing for the business of PHARMACISTS, aside from the necessary service in the shop, with especial view to those who are unable to attend a loulege of Pharmacy?"

This query was answered by Mr. E. Parrish the following year.

(To be continued.) 


\section{THE MINUTES OF THE SESSIONS OF THE SCIENTIFIC SECTION.}

The first session of the Scientific Section was held Tuesday afternoon, August 25th, 1914, in Room D, of the Convention Floor of the Hotel Pontchartrain.

The meeting was called to order by Chairman Ruddiman, at 2:00 p. m., who said :

"Conservation seems to be the word of the times. At this meeting several changes are being inaugurated for the purpose of conserving time, and that is one reason why the present Chairman has broken away from the time honored custom of giving a formal address. The present officers of the Section believe that much of the good to be derived from the meeting is to be found in discussions. In the past many a good paper has been passed by, perhaps, because it was not taken in by the members, or they were not prepared to discuss it. To get the good out of the discussion we must have it at the meeting. I presume that some of you are somewhat like myself; when I see a paper printed, followed by a discussion, I look at the discussion first. I think that the discussion is one of the interesting parts of the paper.

"Then, again, where the writer of a paper is not present to read his paper, it has been the custom to read that paper by title. I think that is not fair to the writer. He has put time and labor into a paper full of good ideas and I think it should be given due consideration.

"I have gone over the papers which have been sent in, particularly those where I knew the writer would not be present, and have made a very brief abstract of the papers with the idea of presenting that brief abstract in case the writer is not present. Then if the members of the Section wish the paper read in full, they may have it read.

"I regret to say that the members of the Association have not coöperated with the officers quite as well as I had hoped for. Up to yesterday morning, only about half of the papers announced on the program had been turned in, consequently the officers have not been in a position to arrange the program to the best advantage, or to select papers for discussion. My idea was to have these papers on hand, and to get some one or two members of the Association to read them over beforehand. in order to be prepared to discuss them in a few words and to the point. That is what we want, I think, in the discussions.

"A resolution introduced at the Nashville meeting will be called up for action some time during the meeting, and this resolution provides or requires that all papers be handed in to the Chairman at least one week before the meeting. I understand there will be a discussion of a similar topic before the Council tonight, and it is proposed to require papers handed in to all sections of the Association, to be handed in one month before the meeting. Probably this will be decided upon at the Council and later at the General Session.

"With these few explanations we will proceed at once to the business.

"The first thing in the order of business, as printed in the by-laws, is the Secretary's report.

"Secretary Scoville: I have no report to make, Mr. Chairman.

"Chairman Ruddiman: The next order of business is the report of standing committees, and Committees of the Association which report to this Section. Some of these reports are rather lengthy, and with the consent of the Section we will postpone these reports until a later session unless there be some objection.

"Mr. Philip Asher: I move that the reports be disposed of in that way."

Motion seconded and carried.

"Chatrman Rudiman: The next order of business is the appointing of a nominating committee, which committee will present two names for each office for the coming year. This Committee is to report before the adjournment of this 
section. On this Committee, I will appoint: Wm. B. Day, of Chicago; Martin I. Wilbert, of Washington; Prof. Jordan.

"The Committee will please report before the adjournment of this Session two names for each of the offices, which are Chairman, First Vice-Chairman, Second Vice-Chairman and Secretary. The election of these will be at the last session of the Section.

"The next order of business is miscellaneous business, and under this, I presume, would come the resolution which was presented at the Nashville meeting at the last session too late to be acted upon. I have already referred to this resolution. It is to change the by-laws requiring the papers to be handed in one week before the meeting. As this subject is to be discussed before the Council to-night, I would suggest that we defer action on this resolution until a later session and see what is best to do to keep in harmony with the General Session.

"Is there any other business to come before the Section? (No response.)

"We will proceed at once to the reading of the papers. The first paper on the program is on the subject of 'Uniformity in Dosage of Radium Emanation,' by Dr. Wm. Jay Schieffelin."

Mr. Schieffelin :-Mr. Chairman and Gentlemen of the Section: I feel that it is a presumption for me to address a gathering of so many scientists and teachers of science; what I have to say is for the men who studied chemistry and physics twenty-five years ago, rather than for those who graduated last spring.

In case I tell you things that many of you know, it will be simply because in speaking of this wonderful subject of radium and its emanation from the point of view of pharmacy, it seems important to refer not only to its properties, but to say a word about its occurrence, and the theory of its existence.

Chairman Ruddiman : Dr. Schieffelin's paper, if there are no objections, will take the usual course. The next paper on the program is "The New Science of Immunology," by Dr. F. E. Stewart, of Philadelphia. (Printed in September issue.)

M. I. Wilbert then read a paper entitled, "Official and Other Tinctures," which was referred for publication.

C. F. Ramsey then read a paper on, "Difficulties in the Manufacture of Certain Fluid Extracts."

Mr. Scoville presented a paper on, "Glycerite of Bismuth." (Printed in September issue.)

Dr. Stockberger read a paper entitled, "Comparison of the Physical Properties of Some Volatile Oils, with Special Reference to the Requirements of the U. S. P., 1910."

A paper was then presented entitled, "A New Method for the Distinction of True From Synthetic Oil of Wintergreen," by G. H. Watson.

Chairman Ruddiman: The next paper on the program is "Laboratory Notes," by George E. E'We, and C. E. Vanderkleed.

Mr. Vanderkleed then read the above paper in abstract.

The Nominating Committee then presented the following nominations for officers for the ensuing year: For Chairman, H. Englehardt, H. C. Hamilton; for Eirst Vice-Chairman: W. L. Scoville, J. H. Turner; for Second Vice-Chairman: L. E. Brown, F. E. Bibbins ; for Secretary: Wm. Mansfield, Azor Thurston.

On motion of Mr. Mansfield the Section adjourned to meet Wednesday afternoon, August 26th, at 2 o'clock. 
SECOND SESSION.

The second session of the Scientific Section was called to order Wednesday afternoon, August 26th, 1914, in Room D, of the Convention Floor, of the Hotel Pontchartrain, by Chairman Ruddiman.

On motion, the minutes of the Secretary were approved.

The following papers were presented:- "The Assay of Opium," by A. R. L. Dohme. (Paper read in abstract by Dr. Englehardt.) And "The Lime Assay of Opium," by A. B. Lyons; which two papers were presented for discussion together by Chairman Ruddiman. "A New Method for the Estimation of Glycerin in Pharmaceutical Preparations," by C. H. Briggs, and "On the Estimation of the Assay of Glycerin," by F. T. Bradt. These two papers were also discussed together. "The Determination of Glycerin in Tablets and in Confections," by LeRoy Forman; "Notes on the Assay of Hydrastis and Fluid Extract of Hydrastis," by H. W. Jones; "What is the Best End-Point of the Reaction in the Frog Heart Method of Digitalis Assay," by L. W| Rowe; "Preliminary Notes on a New Pharmaco-dynamic Method of Assay," by Paul S. Pittinger; "Medicinal Plant Gardens," by Dr. Stockberger, (printed in October issue); "A Third Alkaloid from Gelseminum;" by A. E. Stevenson and L. E. Sayre; "The Necessity of a Method of Estimating the Intrinsic Value of Essential Qualities of Coffee," by Prof. L. E. Sayre. On motion of Mr. Gordon the Section then adjourned to meet on Thursday morning.

THIRD SESSION.

The third session was convened at Room D, Hotel Pontchartrain, Thursday at $9: 30$ a. $\mathrm{m}$.

On motion of $\mathrm{Mr}$. Asher the reading of the minutes of the last session was dispensed with.

Papers were read as follows:-

"Morphine Nitrate and Morphine Acetate," by H. Englehardt and O. E. Winters; "Elementary Phosphorus," by the same authors; the "Estimation of Calomel," by R. I. Grantham.

The Section then elected the following officers for the ensuing year:-Chairman, H. Engelhardt; First Vice-Chairman, W. L. Scoville; Second Vice-Chairman, Linwood E. Brown; Secretary, William Mansfield. The report of the Committee on Medicinal Products was presented and on motion of Mr. Gordon it was accepted to take the usual course. (Report printed in September issue.)

The report of the Committee on Ebert Prize was accepted and referred for publication. (Printed in October issue.)

The report of the Committee on Physiological Testing was received and referred for publication. (Printed in October.)

It was voted to approve the publication of the Digest of Comments on the Pharmacopoia of the United States, published by the Public Health Service of the United States and that a resolution be sent to the Surgeon General to that effect.

The following papers were read in abstract:-"The Glands of Internal Secretion and Their Importance as Therapeutic Agents," by Dr. Cary P. McCord; 
"The Composition and Assay of Diacetyl-Morphine Chloride and Heroin Chloride," by R. T. Harris and A. M. Clover; "The Analysis of Cigarettes, Cigars and Tobacco, and the Use of Lloyd's Reagent in the Determination of Nicotine," by Azor Thurston; "The Structural Variation of Allspice," by Dr. William Mansfield; "Cannabis Sativa, Is the Medicinal Value Found Only in the Indian-Grown Drug ?" by H. G. Hamilton; "The Pharmacognosy of the Medicinal Rhamnus Barks," by Prof. E. N. Gathercoal; "Notes on the Estimation of Morphine and on Lloyd's Reagent," by H. M. Gordin and J. Kaplan; "Notes on a Glycerin "Substitute," by Joseph Feil; "Notes on a New Alkaloid found in Nux Vomica," by Hugo H. Schaefer.

The hour being late it was voted that the remaining papers be considered as read by title and that they be referred for publication.

On motion of $\mathrm{Mr}$. Kirschgessner it was voted to dispense with the formal installation of officers, and that they be considered as installed in office.

Voted to adjourn.

\section{THE DETERMINATION OF GLYCERIN IN TABLETS AND CONFECTIONS.}

LEROY FORMAN.

At the present time the use of glycerin tablets and confections is very great. Upon consulting a number of journals, as well as chemical literature, we find no work of any kind reported upon this class of preparations, which are sold largely through the drug trade.

It is a well recognized fact that glycerin taken in this form has a very soothing effect for irritations of the throat and bronchial tubes.

This investigation was entered upon because there is no available literature on this class of tablets, and, secondly, it was considered as necessary for tablets sold as "Glycerin tablets," to contain an appreciable amount of glycerin, as it is for any medicated tablet to contain an appreciable amount of the chief active constituent for which it is named.

Samples of six different popular brands of such tablets, were purchased in drug stores, two of these samples being plain glycerin tablets, one, honey and glycerin, and three, menthol and glycerin.

The official method of the A. O. A. C. was tried for the estimation of glycerin, but in evaporating the solution, obtained by dissolving the tablets in water, to such a small volume as the A. O. A. C. directs, some glycerin was probably lost, due to the very slow evaporation after the solution had obtained a syrupy consistency, which results when the volume is about $25-30 \mathrm{cc}$. But if milk of lime is added at this time, the resulting mixture can be evaporated to a stiff paste, which can then be carried through the regular $\mathrm{A}$. O. A. C. procedure. The complete method used is as follows:

Enough tablets were taken to weigh about 5 grammes, these were dissolved in water, evaporated to syrupy consistency, $15 \mathrm{cc}$. of milk of lime added and the 